\title{
Forecast foreign exchange with both linear and non- linear models coupled with trading rules for selected currencies
}

\author{
J.Z. Ling ${ }^{\mathrm{a}}$, A.K. Tsui ${ }^{\mathrm{a}}$ and $\underline{\text { Z.Y. Zhang }}{ }^{\mathrm{b}}$ \\ ${ }^{a}$ Department of Economics, National University of Singapore, Singapore \\ ${ }^{b}$ School of Business, Edith Cowan University, Australia \\ Email: zhaoyong.zhang@ecu.edu.au
}

\begin{abstract}
The importance of forecasting exchange rate is evident both academically and practically, but it is not an easy task to perform as the foreign exchange market has long been considered complex, erratic and exhibits apparently random behavior. The challenge is posited in a number of studies that highlight the poor out-of-sample forecasting performance of a variety of structural exchange rate models and conclude that none of these models could significantly outperform a simple random-walk model in both short- and mediumterms. An extensive subsequent literature using non-linear econometric techniques, different currencies, data periodicity and samples also draw similar conclusion that exchange rates, just like other financial time series, can be well modeled using a random walk model.
\end{abstract}

In this paper we attempt to employ a "hybrid" model to investigate the effectiveness of monetary fundamentals and other macroeconomic variables in predicting the bull and bear market longer-term trends (macro-cycles) and in forecasting the exchange rate movements. In particular, we intend to use a combined model of both parametric Markov Logistic model and a nonparametric multilayer feedforward neural network coupled with technical trading rules to predict the macro-cycles of the selected currencies by using the macroeconomic fundamental variables as inputs. When applying the linear models, most existing studies seem to use the same specification for estimation and forecasting, but the dynamic impact of the concerned variables is ignored. In this study we allow for variations in model specification throughout the forecasting period to address this stylized fact, and, furthermore, we combine the linear model and nonlinear neural network model by adopting both an equal weighted approach and a profit weighted approach to capture both the linear and nonlinear components of the exchange rate mechanism. It is expected that the combined hybrid models will outperform those single models in terms of predicting power and trading advantage in different market condition. We choose three pairs of currencies including the US dollar (USD), the Japanese yen (JPY) and Canadian dollar (CAD) in this study. The USD and JPY are one of the mostly traded currencies in the world, and the Canadian dollar is chosen because of its close economic ties to the United States. The bilateral exchange rate of CAD and JPY is studied as it is interesting to see if our model works for the less traded currencies, and also to complete the "triangle" of the three currencies.

The results confirm that the combination models have a significant predictive and market timing ability and outperform the benchmark models in terms of returns, even although their advantage diminishes in the periods of central bank intervention.

Keywords: Forecasting exchange rate, equal weighted composite model, profit weighted composite model, trading macro-cycles, multilayer feedforward neural network 


\section{INTRODUCTION}

The importance of forecasting exchange rate is evident both academically and practically, but it is not an easy task to perform as the foreign exchange market has long been considered complex, erratic and exhibits apparently random behavior. The challenge is posited in the seminal work of Meese and Rogoff (1983a and 1983b) who highlight the poor out-of-sample forecasting performance of a variety of structural exchange rate models and conclude that none of these models could significantly outperform a simple random-walk model in both short- and medium-terms. An extensive subsequent literature using non-linear econometric techniques, different currencies, data periodicity and samples also draw similar conclusion that exchange rates, just like other financial time series, can be well modeled using a random walk model (see, for instance, Cheung, et al., 2005; Engel, et al., 2008).

In this study we attempt to employ a "hybrid" model to investigate the effectiveness of monetary fundamentals and other macroeconomic variables in predicting the bull and bear market longer-term trends (macro-cycles) and in forecasting the exchange rate movements. In particular, we propose a hybrid forecast model consisting of linear regression, multilayer neural network, and combination models to combine with technical trading rule and economic fundamentals to predict the macro-cycles of the selected currencies and investigate the predicative power and market timing ability of the model. When applying the linear models, most existing studies seem to use the same specification for estimation and forecasting, but the dynamic impact of the concerned variables is ignored. In this study we allow for variations in model specification throughout the forecasting period to address this stylized fact, and, furthermore, we combine the linear model and nonlinear neural network model by adopting both an equal weighted approach and a profit weighted approach to capture both the linear and nonlinear components of the exchange rate mechanism. It is expected that the combined hybrid models will outperform those single models in terms of predicting power and trading advantage in different market condition. We choose three pairs of currencies including the US dollar (USD), the Japanese yen (JPY) and Canadian dollar (CAD) in this study. The USD and JPY are one of the mostly traded currencies in the world, and the Canadian dollar is chosen because of its close economic ties to the United States. The bilateral exchange rate of CAD and JPY is studied as it is interesting to see if our model works for the less traded currencies, and also to complete the "triangle" of the three currencies.

This study implies several methodological advantages. First, trading longer-term trends reduces the number of trades required, since we do not adjust trading positions every period. This in turn will reduce transaction costs, especially when a large amount of orders are placed. Then, a simple moving average crossover rule is adopted in the models which will be able to identify the bull and bear macro-cycles in forecasting foreign exchange rates. This rule is widely used by market participants and viewed as a relatively reliable indicator of market trends. By incorporating this trading rule in the models, we will be able to filter trade orders and identify the bull and bear periods of the market. Finally, with this method we will be able to trade at higher frequency if required and reduce noise by trading macro-cycles.

The remainder of this paper is organized as follows. Section 2 provides a literature review of the various models and techniques used to model and forecast exchange rates. In Section 3 we discuss the models and methodology used in this study. Section 4 discusses the data, and section 5 presents the forecasting results and compares the performance of these models. Section 6 provides some concluding remarks.

\section{LITERATURE REVIEW}

\subsection{Technical Trading Rules}

Gençay (1999) found that using simple moving average rules as inputs increases forecast accuracy and improves sign prediction, suggesting that simple technical trading rules can improve forecasts significantly. Others have found that simple technical trading rules can achieve abnormal profits even after accounting for transaction costs. LeBaron (1999) observes, however, that such profits disappear when periods of central bank interventions are taken out of the data set. Neely et al. (2009) conducted a comprehensive study into the profitability of technical trading rules, and concluded that the excess returns documented in various studies were genuine, although their profitability has declined over the years.

\subsection{Linear Models}

Researchers have attempted to model forex market behavior by assuming a linear relationship between the exchange rate dynamic and some fundamental macroeconomic variables like GDP, interest rate, inflation 
rate, money supply or current account balance, but have obtained statistically insignificant estimated coefficients, often with signs different from theoretical expectations, and almost no useful forecasting ability. Guo (2000) claims to have obtained abnormal profits forecasting forex prices using GARCH and Implied Stochastic Volatility Regression models, but finds that after accounting for transaction costs, observed profits are not significantly different from zero. In a paper that examined a number of popular linear models put forward in the nineties, including interest rate parity, productivity based, and composite specification models, Cheung et al. (2005) found that none of the models tested were very successful. Their results showed that some models do well at certain horizons and for certain criteria, and may work for one exchange rate and not another, suggesting that linear models are unable to properly capture the relationship between fundamentals and exchange rates.

\subsection{Nonlinear Models}

\section{(a) Superiority of Nonlinear Models}

Besides traditional econometric models, researchers have begun using neural network models to forecast exchange rates. Kuan \& Liu (1995) used feedforward and recurrent neural networks to forecast five forex rates of the British pound, Deutsche mark, Canadian dollar, Japanese yen, and the Swiss franc against the US dollar, and found that neural networks were able to improve sign predictions and get better forecasts than the random walk model. Hann \& Steurer (1996) compared neural networks to a linear model for US dollar against Deutsche mark forecasts. Their results suggest that, at least when weekly data is used, neural networks are much better than both the monetary and random walk models. The results from Gençay (1999) suggest that neural networks have better forecasting performance than the random walk model or a GARCH(1,1) model in forecasting daily spot exchange rates for the British pound, Deutsche mark, French franc, Japanese yen, and the Swiss franc. El Shazly \& El Shazly (1997) used neural networks to forecast 1 month forex rates and compared the results against the forward rates for three currencies: the British pound, German mark and Japanese yen. They found that the neural network outperformed the forward rate both in terms of accuracy and correctness.

\section{(b) Inputs for Nonlinear models}

Eng et al. (2008) attempted to use a multi-variate ANN with fundamental data such as interest rates and GDP to predict forex price movements. They found that the fundamental data they used were important in exchange rate movements but their underlying relationship to exchange rates were not captured by the ANN. No significant improvement was found in forecasts when fundamental data was used. Ferraro et al. (2011) studied the link between oil prices and exchange rates, in particular the nominal Canadian-U.S dollar exchange rate, and found that oil prices contain valuable information for predicting exchange rates out-ofsample in a country that is a significant oil exporter. Their empirical results show that oil prices can predict the Canadian-U.S dollar nominal exchange rate at a daily frequency, but the predictive power breaks down when monthly or quarterly data is used. Qi \& Wu (2003) attempted to forecast exchange rates at 1-month, 6month and 12-month horizons using variables from the monetary model. They use both a linear model and a neural network model, and find that the models that use fundamental data produce higher RMSE than models that do not, though they show some limited market timing ability. They also find that neural network models perform poorly when used for lower-frequency forecasting.

\subsection{Combination Models}

More recently, there have been a rise in the number of studies that use combination (also called ensemble) models - more than one model is used for prediction and the forecasts of each individual model is weighted to arrive at a final prediction. The basic concept behind this is that different models have unique capabilities and better capture different patterns in the data, and by combining their forecasts, in theory, one should get a more reliable prediction. Clemen (1989) provided an early review and description of combined forecasting. As a result of the advantages of combined forecasting, many researchers have attempted to reduce variance using composite forecasts. Khashei et al. (2009) constructed a hybrid model by combining ARIMA, ANN, and fuzzy logic models and used it to forecast US Dollar and Euro against Iranian Rial and gold prices. They found that the hybrid model outperforms any of the single models. Yu et al. (2005) integrated a generalized linear auto regression model with ANNs in forex forecasting. Their findings once again show that nonlinear ensemble models outperform the other individual models. 


\section{METHODOLOGY AND THE MODEL}

In this section we discuss the model development. We first examine how to use the self-adjusting Markov logit model (ML) and the neural network model (NN) to identify the state of current market cycle, i.e., the bullish or bearish state by carefully assessing the inclusion of variables as inputs. We then discuss two different weighting methods used to derive our combination models, which will be used to predict the macrocycles of the selected currencies and assess the predicative power and market timing ability of the model. We eventually assess the performance of each individual model and the combination models by comparing their respective trading results. Figure 1 presents the structure of this study. In all the models, the dependent variable will be the state of the current market cycle - whether it is bull or bear. We assign a value of 1 to the bull market and 0 to the bear market, and then include in the study a total of 4 "complex" models, namely, the self-adjusting Markov Logit model (ML), the neural network model (NN), the equal weighted combination model (ECM), and the profit-weighted combination model (PCM). Inputs lagged by one time period are used in order to keep our models simple. We first feed our inputs into the ML and NN models to get predictions for the probability of a bull market, and obtain trading results based on these predictions. Then, we use the ML and NN predictions in the combination models to get predictions of the probability of a bull market, and obtain trading results. Finally, we compare the trading results and assess the models performance.

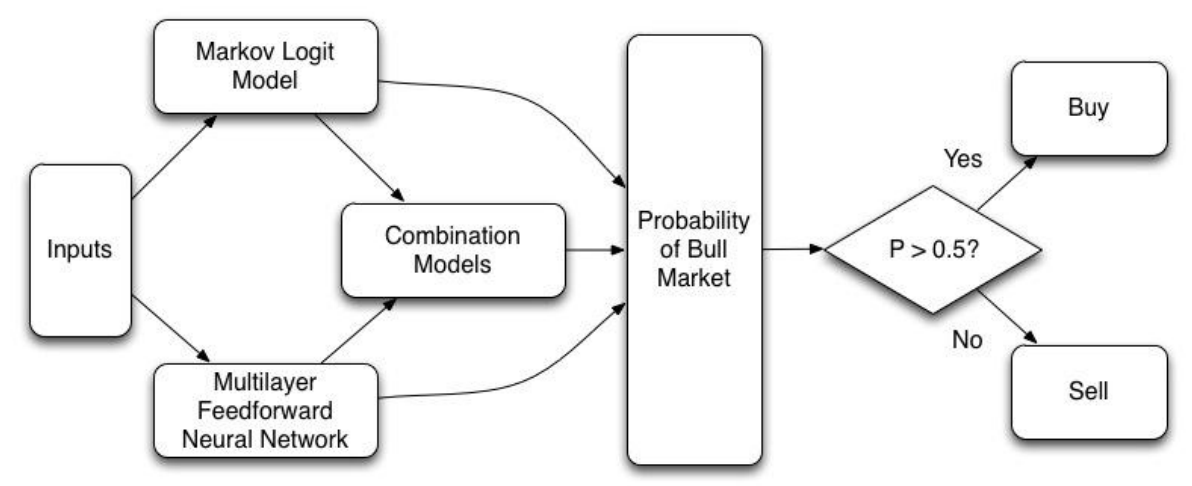

Figure 1. Overview of the Model Development

We set the following Markov logit regression model to reflect these effects on the probability of a bullish market state:

$$
\pi_{q t}=\operatorname{Pr}\left[S_{t}=u \mid S_{t-1}=q, x_{t-1}\right]=f\left(\beta_{q}^{r} \cdot x_{t-1}\right)=f(z)
$$

where $\pi_{q t}$ is the probability of the market state at time $t q=u, d$, where $u$ denotes a bull market and $d$ denotes a bear market, and $S_{t}$ represents the state of the market at time $t ; x_{t-1}$ represents the vector of lagged explanatory variables, with the first term being a constant to capture the intercept term; $\beta_{q}$ is the coefficient vector to capture the time varying effects of the explanatory variables in different states; and $f$ represents the logistic function. We define a bull market if the probability of a bull market is larger than 0.5 , and otherwise a bear market, namely,

$$
\begin{aligned}
& \text { If } \pi_{q t+1}>0.5, \text { predicted state }=\text { bull, } S_{t+1}=1 \\
& \text { If } \pi_{q t+1} \leq 0.5, \text { predicted state }=\text { bear, } S_{t+1}=0
\end{aligned}
$$

The different market status will then determine the corresponding investment strategy which is used to assess the predictive accuracy performance of the models. The variable $\mathrm{z}$ in equation (1) is defined as: 
Ling et al., Forecast foreign exchange with both linear and non-linear models coupled with trading rules

$$
\begin{gathered}
z=\beta_{d 0}+\beta_{u 0} D_{0}+\beta_{d 1} X_{1, t-1}+\beta_{u 1} D_{1} X_{1, t-1}+B_{d 2} X_{2, t-1}+\beta_{u 2} D_{2} X_{2, t-1}+\cdots \\
+\beta_{d k} X_{k, t-1}+\beta_{u k} D_{k} X_{k, t-1}+\varepsilon_{t}
\end{gathered}
$$

where $D_{k}$ is a dummy variable that equals 1 if the previous state is a bull market and 0 if the previous state is a bear market. Thus, the coefficient for a particular variable $X_{k, t-1}$ is the summation of the coefficients on $X_{k, t-1}$ and $D_{k} X_{k, t-1}$, and the coefficient for the same variable in a bear market is just the coefficient on $X_{k, t-1} \cdot \varepsilon_{t}$ is the error term.

\section{DATA AND EMPIRICAL ANALYSIS}

\subsection{Data description}

In this paper we use three pairs of weekly exchange rates including the US dollar (USD), the Japanese yen (JPY) and the Canadian dollar (CAD) obtained from Datastream spanning from $1^{\text {st }}$ January 1993 to $25^{\text {th }}$ January 2013. As we are more concerned about the longer-term cycles of the currency-pair movements, the weekly exchange rates will allow us to better manage the sample size issue than the monthly data, and also have not much unnecessary noise as with the daily data. We take the exchange rates at the end of the week in our study. Table 1 gives a brief outline of the number of periods, window size for ML model, sample length, and sample periods for each currency pair.

As regards the macroeconomic variables, we use 10-year government bond and 3-month treasury bill differentials, year over year (YoY) CPI growth differentials, YoY M1 growth differentials and YoY industrial production growth respectively to proxy the interest rate differentials, relative price level, relative money supply and relative real income in the popular monetary model. ${ }^{1}$ As Japan does not have 3-month treasury bills, we use the Table 1: Summary of Sample Periods

\begin{tabular}{|c|c|c|c|}
\hline & USD/CAD & USD/JPY & CAD/JPY \\
\hline $\begin{array}{l}\text { Sample Period } \\
\text { (weeks) }\end{array}$ & 982 & 1048 & 982 \\
\hline ML Window Size & 654 & 698 & 654 \\
\hline $\begin{array}{l}\text { In-Sample Period } \\
\text { (weeks) }\end{array}$ & 164 & 175 & 164 \\
\hline In-sample Start Date & 21 July, 2006 & 19 May, 2006 & 21 July, 2006 \\
\hline In-Sample End Date & $\begin{array}{l}\text { 4 September, } \\
2009\end{array}$ & $\begin{array}{l}18 \text { September, } \\
2009\end{array}$ & $\begin{array}{l}4 \text { September, } \\
2009\end{array}$ \\
\hline $\begin{array}{l}\text { Out-of-Sample Period } \\
\text { (weeks) }\end{array}$ & 164 & 175 & 164 \\
\hline $\begin{array}{c}\text { Out-of-Sample Start } \\
\text { Date }\end{array}$ & $\begin{array}{c}\text { 11 September, } \\
2009 \\
\end{array}$ & $\begin{array}{l}25 \text { September, } \\
2009\end{array}$ & $\begin{array}{c}11 \text { September, } \\
2009\end{array}$ \\
\hline $\begin{array}{c}\text { Out-of-Sample End } \\
\text { Date }\end{array}$ & $\begin{array}{l}26 \text { October, } \\
2012\end{array}$ & $\begin{array}{l}25 \text { January, } \\
2013\end{array}$ & $\begin{array}{l}26 \text { October, } \\
2012\end{array}$ \\
\hline
\end{tabular}
Japanese Interbank 3-month rate provided by the British Bankers' Association. In addition, following Ferraro et al. (2011), we also include oil prices as one of our input variables. Canada is the sixth largest oil producing country in the world, and the largest single source of oil imports into the United States. More effect is expected from the oil prices changes onto the exchange rate. Although there is inconclusive and mixed evidence of correlation between stock markets and foreign exchange markets, we include stock market returns in our empirical study which are proxied by the S\&P500, Nikkei, and S\&P/TSX Composite indexes, respectively. We have also employed the augmented Dickey-Fuller (ADF) and the Efficient Modified Phillips-Perron (PP) tests to check the stationarity of all the series. Our findings, available upon request, show that all ADF and PP test statistics are significant at the $1 \%$ level, thereby indicating that all the return series are stationary.

We estimate the models to determine the predictive accuracy of the bull/bear market states in terms of the percentage of bull/bear states that the model predicts correctly. We compare directional accuracy of each model, which is critical to successful trading. The first two-thirds of the data are used to perform the initial regression and training of the neural network, and the rest of the data are used to check for the predictive accuracy of the models and for out-of-sample forecasting. We also conduct the Pesaran-Timmermann (PT)

\footnotetext{
${ }^{1} \mathrm{Qi}$ and $\mathrm{Wu}(2003)$ also use similar variables in their study.
} 
Ling et al., Forecast foreign exchange with both linear and non-linear models coupled with trading rules

(1992) predictive failure test to determine whether a model is a significantly powerful predictor of the sign. We do not use RMSE because it does not make sense to compare RMSE for a binary model like the ones we are using. Table 2 reports predictive accuracy statistics.

As expected, the predictive accuracy for USD/CAD is found to be generally higher than others across the board due to the low number of cycle switches, and the directional accuracy for 100-SMA is also better than for 50-SMA. We observe that across both classification methods the complex models outperform the benchmark model. With the exception of the NN model for 50-SMA, all complex models have significant market-timing ability for in-sample validation periods according to the PT-test. However, for forecasting, only the PCM model has significant predictive power across all the classification methods. In terms of consistency, the PCM model

\begin{tabular}{|c|c|c|c|c|c|c|c|c|c|c|}
\hline & \multicolumn{5}{|c|}{ In-Sample (Bull - 95 / Bear - 69) } & \multicolumn{5}{|c|}{ Out-of-Sample (Bull - 41 / Bear - 123) } \\
\hline & ML & BM & NN & ECM & PCM & ML & BM & NN & ECM & PCM \\
\hline \% Bull Correct & 46.32 & 52.63 & 93.68 & 48.42 & 72.63 & 21.95 & 21.95 & 92.68 & 21.95 & 53.66 \\
\hline$\%$ Bear Correct & 76.81 & 63.77 & 7.25 & 72.46 & 60.87 & 67.48 & 67.48 & 4.07 & 65.85 & 63.41 \\
\hline DA $(\%)$ & 59.15 & 57.32 & 57.32 & 58.54 & 67.68 & 56.10 & 56.10 & 26.22 & 54.88 & 60.98 \\
\hline Buy-hold \% & 57.93 & 57.93 & 57.93 & 57.93 & 57.93 & 25.00 & 25.00 & 25.00 & 25.00 & 25.00 \\
\hline \multirow[t]{4}{*}{ PT-test Stat } & 3.04 & 2.09 & 0.24 & 2.71 & 4.31 & -1.28 & -1.28 & -0.84 & -1.47 & 1.93 \\
\hline & & & & D/CAD & $100 \mathrm{SMA}$ & & & & & \\
\hline & \multicolumn{5}{|c|}{ In-Sample (Bull - 96/ Bear - 68) } & \multicolumn{5}{|c|}{ Out-of-Sample (Bull - 32 / Bear 132) } \\
\hline & ML & BM & $\mathrm{NN}$ & ECM & PCM & ML & BM & NN & ECM & PCM \\
\hline \% Bull Correct & 39.58 & 27.08 & 45.83 & 38.54 & 48.96 & 21.88 & 21.88 & 3.13 & 21.88 & 21.88 \\
\hline$\%$ Bear Correct & 82.35 & 52.94 & 80.88 & 82.35 & 82.35 & 84.85 & 84.85 & 97.73 & 84.85 & 87.88 \\
\hline DA $(\%)$ & 57.32 & 37.80 & 60.37 & 56.71 & 62.80 & 72.56 & 72.56 & 79.27 & 72.56 & 75.00 \\
\hline Buy-hold \% & 58.54 & 58.54 & 58.54 & 58.54 & 58.54 & 19.51 & 19.51 & 19.51 & 19.51 & 19.51 \\
\hline PT-test Stat & 3.02 & -2.64 & 3.55 & 2.89 & 4.13 & 0.92 & 0.92 & 0.28 & 0.92 & 1.43 \\
\hline \multicolumn{11}{|c|}{$\begin{array}{r}\text { USD/JPY } \\
\end{array}$} \\
\hline & \multicolumn{5}{|c|}{ In-Sample (Bull - 86 / Bear - 89) } & \multicolumn{5}{|c|}{ Out-of-Sample (Bull - 93 / Bear - 82) } \\
\hline & ML & BM & NN & ECM & PCM & ML & BM & $\mathrm{NN}$ & ECM & PCM \\
\hline$\%$ Bull Correct & 63.95 & 63.95 & 93.02 & & 81.40 & 45.16 & 45.16 & 95.70 & & 70.97 \\
\hline$\%$ Bear Correct & 66.29 & 66.29 & 19.10 & 66.29 & 48.31 & 53.66 & 41.46 & 17.07 & 52.44 & 51.22 \\
\hline DA $(\%)$ & 65.14 & 65.14 & 55.43 & 65.14 & 64.57 & 49.14 & 43.43 & 58.86 & 48.57 & 61.71 \\
\hline Buy-hold \% & 49.14 & 49.14 & 49.14 & 49.14 & 49.14 & 53.14 & 53.14 & 53.14 & 53.14 & 53.14 \\
\hline PT-test Stat & 4.01 & 4.01 & 2.38 & 4.01 & 4.17 & -0.16 & -1.77 & 2.78 & -0.32 & 3.01 \\
\hline \multicolumn{11}{|c|}{ USD/JPY 100 SMA } \\
\hline & \multicolumn{5}{|c|}{ In-Sample (Bull - 115/ Bear - 60) } & \multicolumn{5}{|c|}{ Out-of-Sample (Bull - 106 / Bear - 69) } \\
\hline & ML & BM & $\mathrm{NN}$ & ECM & PCM & ML & BM & NN & ECM & PCM \\
\hline$\%$ Bull Correct & 68.70 & 68.70 & 73.91 & 68.70 & 90.43 & 38.68 & 23.58 & 83.02 & 37.74 & 66.98 \\
\hline$\%$ Bear Correct & 80.00 & 80.00 & 53.33 & 80.00 & 88.33 & 59.42 & 59.42 & 27.54 & 59.42 & 59.42 \\
\hline & 72.57 & 72.57 & 66.86 & 72.57 & & 46.86 & 37.71 & 61.14 & 46.29 & 64.00 \\
\hline Buy-hold \% & 65.71 & 65.71 & 65.71 & 65.71 & 65.71 & 60.57 & 60.57 & 60.57 & 60.57 & 60.57 \\
\hline PT-test Stat & 6.14 & 6.14 & 3.59 & 6.14 & 10.30 & -0.25 & -2.40 & 1.68 & -0.38 & 3.45 \\
\hline \multicolumn{11}{|c|}{ CAD/JPY 50 SMA } \\
\hline & \multicolumn{5}{|c|}{ In-Sample (Bull - 77 / Bear - 87) } & \multicolumn{5}{|c|}{ Out-of-Sample (Bull - 80 / Bear - 84) } \\
\hline & ML & $\mathrm{BM}$ & NN & ECM & PCM & $\mathrm{ML}$ & $\mathrm{BM}$ & NN & ECM & PCM \\
\hline$\%$ Bull Correct & 59.74 & 59.74 & 64.94 & 55.84 & 63.64 & 36.25 & 36.25 & 76.25 & 20.00 & 60.00 \\
\hline$\%$ Bear Correct & 67.82 & 67.82 & 55.17 & 67.82 & 59.77 & 54.76 & 40.48 & 22.62 & 66.67 & 54.76 \\
\hline DA (\%) & 64.02 & 64.02 & 59.76 & 62.20 & 61.59 & 45.73 & 38.41 & 48.78 & 43.90 & 57.32 \\
\hline Buy-hold \% & 46.95 & 46.95 & 46.95 & 46.95 & 46.95 & 48.78 & 48.78 & 48.78 & 48.78 & 48.78 \\
\hline PT-test Stat & 3.55 & 3.55 & 2.59 & 3.06 & 3.00 & -1.17 & -2.99 & -0.17 & -1.93 & 1.90 \\
\hline \multicolumn{11}{|c|}{ CAD/JPY 100 SMA } \\
\hline & \multicolumn{5}{|c|}{ In-Sample (Bull - 104 / Bear - 60) } & \multicolumn{5}{|c|}{ Out-of-Sample (Bull - 94 / Bear 70) } \\
\hline & ML & BM & $\mathrm{NN}$ & ECM & PCM & ML & $\mathrm{BM}$ & $\mathrm{NN}$ & ECM & PCM \\
\hline$\%$ Bull Correct & 82.69 & 67.31 & 87.50 & 98.08 & 97.12 & 32.98 & 13.83 & 100.00 & 67.02 & 67.02 \\
\hline \% Bear Correct & 76.67 & 80.00 & 41.67 & 70.00 & 76.67 & 60.00 & 60.00 & 0.00 & 25.71 & 52.86 \\
\hline DA (\%) & 80.49 & 71.95 & 70.73 & 87.80 & 89.63 & 44.51 & 33.54 & 57.32 & 49.39 & 60.98 \\
\hline Buy-hold \% & 63.41 & 63.41 & 63.41 & 63.41 & 63.41 & 57.32 & 57.32 & 57.32 & 57.32 & 57.32 \\
\hline PT-test Stat & 7.53 & 5.85 & 4.28 & 9.51 & 9.97 & -0.93 & -3.84 & Inf & -1.01 & 2.56 \\
\hline
\end{tabular}

Note: The table reports the predictive accuracy of the Markov Logit (ML), benchmark (BM), neural network (NN), equal weighted combination (ECM), and profit weighted combination models (PCM). The bracketed numbers indicate the quantity of bull and bear periods in the sample. The numbers in bold indicate the best perform performance of the 5 models for the particular category. DA refers to the directional accuracy statistic. PT-tes $2.33,1.645$ and 1.282 , respectively. Boldened PT-test statistic indicates significant values.

seems to perform the best under all circumstances. It is interesting to note that although the PCM model did not achieve the best directional accuracy statistic (DA) for the 100-SMA classification during out-of-sample forecasting, it is still the only model that has significant predictive power according to the PT-test. This is because the PT-test does not simply depend on directional accuracy, but also takes into account the probability of a model making the right classification.

For the USD/JPY, it is noted in Table 2 that, largely due to the number of cycle changes, the overall predictive accuracy is poorer than in the case of USD/CAD. In terms of predictive accuracy, the 100-SMA again seems to marginally edge the 50-SMA due to its inherent advantage, though surprisingly it does not give significantly better DA scores for out-of-sample forecasting, with the exception of the naïve benchmark model. This suggests that out-of-sample forecasting of the complex models using 50-SMA is able to overcome the advantage that less volatility gives 100-SMA. Out-of-sample forecasting DA is markedly worse than the in-sample. The ML model has the best in-sample performance in terms of directional accuracy for 50-SMA, but loses out to the PCM for out-of-sample forecasting. We note that, although most models have significant predictive power for in-sample performance according to the PT-test, only the PCM and NN models show a significant predictive ability for out-of-sample forecasting. This, together with PCM's high DA scores, suggests that, out of the 5 models, the PCM is likely the best for out-of-sample forecasting. Similarly, the results for CAD/JPY show that, although all the models have a significant predictive power for in-sample forecasting, the PCM model apparently outperform the rest of the models in both 50 SMA and 100 SMA, with the DA being the highest for out-of-sample forecasting in both cases.

We have also examined the investment performance of these models, and their market timing abilities. The results (not reported but available upon request) show that the PCM outperforms all the other models in terms of annualized and accumulative returns in out-of-sample forecasting with the 100 SMA trading rules for all the currencies and the same for applying the $50 \mathrm{SMA}$ rules with the exception of USD/CAD. It is also noted that the PCM shows a better performance and return for the given risk, judging from the high Sharpe ratio. The PCM model predicts correctly a bull market in late 2007 well before the benchmark model for the in- 
sample period, and again successfully predicts a bear market in late 2008 and early 2009 ahead of the benchmark model or even the actual state, which confirms its market-timing ability. In the out-of-sample forecasting period, the PCM model also outperforms the benchmark model in predicting market state change from bullish to bearish market in 2011 and 2012. These findings further confirm the better predictive and market-timing abilities of the PCM model than the benchmark model, which have eventually led to the high return.

\section{CONCLUDING REMARKS}

We have employed a combined model of both parametric Markov Logistic model and a nonparametric multilayer feedforward neural network coupled with technical trading rules to predict the macro-cycles of three selected currencies, namely, USD/CAD, USD/JPY and CAD/JPY by using the macroeconomic fundamental variables as inputs. The results confirm that the combination models have a significant predictive and market timing ability and outperform the benchmark models in terms of returns, even although their advantage diminishes in the periods of central bank intervention.

\section{REFERENCES}

Bartov, E., and G.M. Bodnar (1994). Firm Valuation, Earnings Expectations, and the Exchange-Rate Exposure Effect. The Journal of Finance, 49 (5), 1755-1785.

Cheung, Y.-W., M.D. Chinn and A.G. Pascual (2005). Empirical exchange rate models of the nineties: Are any fit to survive? Journal of International Money and Finance, 24 (7), 1150-1175.

Clemen, R. T. (1989). Combining forecasts: A review and annotated bibliography. International Journal of Forecasting, 5 (4), 559-583.

El Shazly, M. R. and H.E. El Shazly. (1997). Comparing the forecasting performance of neural networks and forward exchange rates. Journal of Multinational Financial Management, 7 (4), 345-356.

Eng, M. H., Y. Li, Q.G. Wang and T. Lee. (2008). Forecast Forex With ANN Using Fundamental Data. International Conference on Information Management, Innovation Management and Industrial Engineering, 1, pp. 279-282.

Engel, C., C. Nelson and K.D. Mark. (2008). West Exchange Rate Models Are Not As Bad As You Think. In: Acemoglu, D., Rogoff, K., Woodford, M. (Eds.), NBER Macroeconomics Annual 2007. MIT Press, Cambridge, MA, pp. 381-441.

Ferraro, D., B. Rossi andK. Rogoff. (2011). Can Oil Prices Forecast Exchange Rates? Economic Research Initiatives at Duke Working Paper (95).

Gençay, R. (1999). Linear, non-linear and essential foreign exchange rate prediction with simple technical trading rules. Journal of International Economics, 47 (1), 91-107.

Guo, D. (2000). Dynamic Volatility Trading Strategies in the Currency Option Market. Review of Derivatives Research (4), 133-154.

Hann, T. H. and E. Steurer. (1996). Much ado about nothing? Exchange rate forecasting: Neural networks vs. linear models using monthly and weekly data. Neurocomputing, 10 (4), 323-339.

Kuan, C.-M. and T. Liu. (1995). Forecasting exchange rates using feedforward and recurrent neural networks. Journal of Applied Econometrics, 10 (4), 347-364.

LeBaron, B. (1999). Technical trading rule profitability and foreign exchange intervention. Journal of International Economics (49), 125-143.

Meese, R.A. and K. Rogoff (1983a). Empirical Exchange Rate Models of the Seventies: Do They Fit Out of Sample?, Journal of International Economics 14, 3-24.

Meese, R.A., and K. Rogoff (1983b).The Out-of-Sample Failure of Empirical Exchange Rate Models: Sampling Error or Misspecification, in J. A. Frenkel, (ed.) Exchange Rates and International Macroeconomics (Chicago: University of Chicago Press).

Neely, C. J., P.A. Weller and J.M. Ulrich. (2009). The Adaptive Markets Hypothesis: Evidence from the Foreign Exchange Market. Journal of Financial and Quantitative Analysis, 44 (2), 467-488.

Pesaran, M. and A. Timmermann. (1992). A Simple Nonparametric Test of Predictive Performance. Journal of Business \& Economic Statistics, 10 (4), 461-465.

Qi, M. and Y. Wu. (2003). Nonlinear prediction of exchange rates with monetary fundamentals. Journal of Empirical Finance, 623-640.

Yu, L., S. Wang and K. Lai. (2005). A novel nonlinear ensemble forecasting model incorporating GLAR and ANN for foreign exchange rates. Computers \& Operations Research, 32 (10), 2523-2541. 